\title{
Study of correlation between new born size and maternal first trimester haemoglobin concentration
}

\author{
Shweta Kallurkar
}

Assistant Professor, Department of Obstetrics, Dr VMMC Solapur, Maharashtra, INDIA. Email: shwetakallurkar393@gmail.com

\begin{abstract}
Background: India has reported high prevalence of anemia in. Methods: Prospective observational study, included 150 mothers registered for antenatal care (ANC) and willing to continue till confinement were recruited, and subjected to completed hemogram and red cell indices. We followed up these mothers till delivery and looked into the gestation and newborn anthropometry. Statistical analysis was done using Students t-test and chi x-test. Observation and Analysis: In study of 150 cases, 54\% were anemic. In first trimester, prevalence of anemia was 68/150 cases (45.34\%). In anemic mothers, low birth weight babies were $25 / 37$ (67.56\%) while in non-anemic mothers low birth weight babies were $12 / 37$ $(32.43 \%)(p<0.010)$ Conclusion: Increased incidence of low birth weight and preterm babies is seen if the mother is anemic in her first trimester
\end{abstract}

Address for Correspondence:

Dr. Shweta Kallurkar, Assistant Professor, Department of Obstetrics, Dr VMMC Solapur, Maharashtra, INDIA.

Email: shwetakallurkar393@gmail.com

Received Date: 13/12/2019 Revised Date: 10/01/2020 Accepted Date: 02/02/2020

DOI: https://doi.org/10.26611/10121513

This work is licensed under a Creative Commons Attribution-NonCommercial 4.0 International License. (oc) BY-NC

\begin{tabular}{|l|l|}
\hline \multicolumn{2}{|c|}{ Access this article online } \\
\hline Quick Response Code: & Website: \\
\hline & www.medpulse.in \\
\hline
\end{tabular}

\section{INTRODUCTION}

Anemia is one of the most frequently observed nutritional deficiency disease in the world today. It is major public health problem worldwide. Iron deficiency starts in childhood, worsens in adolescence and gets aggravated in pregnancy. The global prevalence of anemia during pregnancy is estimated by the World Health Organization is $47.4 \%$. It is present among women in reproductive age group, particularly during pregnancy, and often become a contributory cause for maternal death (WHO, 1992). Anemia being one of the major contributory factors for maternal morbidity and mortality. Every Second women is anemic (55\%).Evidence from stable-isotope studies suggest that the percentage of non-heme iron absorbed from food during normal pregnancy increases from $7 \%$ at 12 weeks of gestation to $36 \%$ at 24 weeks and $66 \%$ at 36 wks. These dramatic changes enable the healthy pregnant woman to cope with the extra demands of pregnancy without becoming anemic ${ }^{1}$, but only if there is adequate iron in her diet. ${ }^{1}$ Prevalence of anemia in South Asian countries is the highest in the world. WHO estimates that even among the South Asian countries, India has the highest prevalence of anemia.2 NNMB (National Nutrition Monitoring Bureau), DLHS (District Level Household Survey) and ICMR (Indian Council of Medical Research) surveys showed that over $87 \%$ of pregnant women suffer from anemia and about $10 \%$ have severe anemia. ${ }^{2}$ The importance of adequate plasma volume expansion in allowing adequate fetal growth is attested by several studies that showed an increased incidence of low birth weight in association with either a high maternal hemoglobin concentration ${ }^{3,4,5}$ or high hematocrit. ${ }^{6}$ Maternal blood is supplied to the intervillous space of the placenta by spiral arteries, which provides low pressure flow. Failure of the plasma volume to expand (and of the hemoglobin concentration to drop) is associated with a $\leq 3$-fold increase in the incidence of preeclampsia in pregnancy. ${ }^{7}$ It has been suggested that a high blood viscosity may reduce the perfusion of the placenta, which may lead to intrauterine growth restriction. There are some controversial reports about the association between maternal hematocrit and adverse outcome of pregnancy ${ }^{8,9}$ 


\section{MATERIALS AND METHODS}

Prospective observational study, conducted in department of Obstetrics, Dr V.M.M.C Solapur India, during June 2018 to June 2019 after ethical committee approval, included 200 mothers registered for antenatal care (ANC) and willing to continue till confinement were recruited after written informed consent as per routine protocol. In this study, cases with hemoglobin $>11 \mathrm{gm} \%$ and $<11$ $\mathrm{gm} \%$ were classified as normal and anemia respectively in first trimester of pregnancy.

\section{INCLUSION CRITERIA}

1. All pregnant women registered to our institute for ANC till deliveries were included in the Study.

2. Cases of all types of anemia including hemolytic anemia.

3. Singleton pregnancy

4. Having had a USG in first trimester to accurately confirm / adjust dates and assign gestational age accordingly

\section{EXCLUSION CRITERIA}

Pregnant women with one of the following at booking were excluded:

1. Diabetes mellitus.

2. Hypertension (including pregnancy-induced hypertension).
3. Toxoplasmosis, Rubella, Cytomegalovirus, Herpes infection.

4. Diagnosed renal or cardiac illness.

5. Smoker or alcoholic.

6. Multiple gestation.

\section{THE INVESTIGATIONS DONE WERE}

\section{Blood-}

a) Measurement of hemoglobin concentration was done by cyanomethemoglobin method (Analyzer-Coulter).

b) Complete blood picture- $\mathrm{MCV}, \mathrm{MCH}, \mathrm{MCHC}$, RDW.

c) Hematocrit (Hct).

d) Peripheral smear for typing of anemia.

e) Hemoglobin electrophoresis whenever required. Birth weight was recorded in grams using a digital scale with a scale of 1 gram. As per weight of newborns categorization was done as normal if birth weight is above $2.5 \mathrm{~kg}$ and low birth weight if less than $2.5 \mathrm{~kg}$.

\section{STATISTICAL ANALYSIS}

The correlation between hemoglobin concentration and birth weight and other anthropometric parameters was measured by using chi test and students- $t$ test. $P$ value was considered significant if it was below 0.05 and highly significant in case $<0.001$

\section{OBSERVATION AND RESULTS}

Table 1: Percentage of severity of anemia in our study as per severity assessment by WHO classification

\begin{tabular}{cc}
\hline Haemoglobin level & First Trimester( $\mathbf{n = 2 0 0 )}$ \\
\hline Normal( $>11.1$ gm\%) & $112(56 \%)$ \\
Mild(9.1-11 gm\%) & $68(34 \%)$ \\
Moderate(7.1-9 gm\%) & $20(10 \%)$ \\
Severe(4.1-7 gm\%) & $0(0 \%)$ \\
\hline Total & 200
\end{tabular}

Table 2: First trimester hemoglobin concentration and outcome in the form of birth weight of baby and maturity

\begin{tabular}{|c|c|c|c|c|c|}
\hline $\mathrm{Hb} \%$ & $\begin{array}{c}<7.0 \mathrm{gm} \% \\
(\mathrm{n}=0)\end{array}$ & $\begin{array}{c}7.1-9.0 \mathrm{gm} \% \\
(\mathrm{n}=20)\end{array}$ & $\begin{array}{c}\text { 9.1-11 gm\% } \\
\text { (68 }\end{array}$ & $\begin{array}{c}\begin{array}{c}11.1-13 \mathrm{gm} \% \\
(n=92)\end{array} \\
\end{array}$ & $\begin{array}{c}>13 \text { gm\% } \\
(n=20)\end{array}$ \\
\hline & & $8.12 \pm 0.48$ & $10.12 \pm 0.15$ & $11.82 \pm 0.51$ & $13.52 \pm 0.72$ \\
\hline Mean birth weight in gm & - & $2248 \pm 123.32$ & $2775 \pm 399.52$ & $2872 \pm 371.52$ & $2651 \pm 213.12$ \\
\hline $\begin{array}{c}\text { Birth } w t<2500 \text { gms } \\
\qquad(n=58)\end{array}$ & - & $2014 \pm 105(n=22)$ & $2215 \pm 145(n=20)$ & $2289 \pm 101.52(n=10)$ & $2269 \pm 209.51(n=6)$ \\
\hline $\begin{array}{c}\text { Birth wt }>2500 \text { gm } \\
\quad(n=142)\end{array}$ & - & $\begin{array}{c}3140 \pm 1.02 \\
(n=5)\end{array}$ & $\begin{array}{c}2945 \pm 195 \\
(62)\end{array}$ & $\begin{array}{c}2972 \pm 275.86 \\
(n=72)\end{array}$ & $\begin{array}{c}27.01 \pm 151.42 \\
(n=3)\end{array}$ \\
\hline Preterm $(n=39)$ & -- & 6 & 17 & 13 & 3 \\
\hline $\operatorname{Term}(n=161)$ & & 12 & 61 & 76 & 12 \\
\hline
\end{tabular}

Out of 200 pregnant women enrolled in study after their consent, 146(73\%) of them belongs to the age group of 21-30 years, elderly primigravida cases were $12,(6 \%), 154(77 \%)$ were primiparous and remaining $34(17 \%)$ case were multiparous. The correlation between hemoglobin concentration and birth weight and other anthropometric parameters was measured by using chi square test and student's t-test. P-value was considered significant if it was below and highly significant in case $<0.001$.

\section{DISCUSSION}

Effect of first trimester hemoglobin percentage on newborn size and pregnancy outcome-In first trimester prevalence of anemia i.e. $\mathrm{Hb}<11 \mathrm{gm} \%$ were $44 \%(88$ cases) and normal range $\mathrm{Hb}>11 \mathrm{gm} \%$ (non-anemic) were $56 \%$ (112 cases). In anemic mothers low birth weight 
babies were 42 out of total 58 . While in non-anemic mothers low birth weight babies were 16 of 58 i.e. $27.58 \%$, statistically significant difference noted $(\mathrm{p}<0.01)$. Of total 142 normal birth weight babies, born in anemic and non-anemic mothers were $67(33.5 \%)$ and 75 $(66.50 \%)$ respectively, difference is statistically significant $(\mathrm{p}<0.01)$. Out of 39 preterm babies, 23 babies (58.97\%) born to anemic mothers and 16 babies (41.03\%) born to non-anemic mothers, difference is statistically significant $(p<0.01)$ In our study, we observed that as hemoglobin percentage of mother increases, birth weight of baby increases $(\mathrm{p}<0.001)$.In cases with $\mathrm{Hb}$ between 7.1 to $9 \mathrm{gm} \%$ (moderate anemia) mean birth weight of LBW babies were $2181 \pm 205 \mathrm{gms}$, and that of normal babies was $3140 \pm 0.0 \mathrm{gms} \quad(\mathrm{p}<0.001)$. In cases with hemoglobin between 9.1 to $11 \mathrm{gm} \%$ (mild anemia) mean birth weight of LBW and normal babies were $2212 \pm 142 \mathrm{gms}$ and $2930 \pm 292$ gms respectively $(\mathrm{p}<0.001)$. Ronnenberg AG et al ${ }^{10} 2004$ (China) observed that both mild and moderate anemia were significantly associated with lower birth weight. In cases with hemoglobin between $11.1 \mathrm{gm} \%$ to $13 \mathrm{gm} \%$ mean birth weight of LBW and normal babies were $2280 \pm 111 \mathrm{gms}$ and $2962 \pm 311 \mathrm{gms}$ respectively $(\mathrm{P}<0.001)$. In cases with hemoglobin above $13.0 \mathrm{gm} \%$ mean birth weight of LBW babies and of normal babies were $2270 \pm 210 \mathrm{gms}$ and $2707 \pm 210 \mathrm{gms}$ respectively $(\mathrm{p}<0.002)$. Murphy JF et $a l^{7}$ studied relation of hemoglobin levels in first and second trimesters to outcome of pregnancy and found both high (greater than $13.2 \mathrm{~g} / \mathrm{dl}$ ) and low (less than $10.4 \mathrm{~g} / \mathrm{dl}$ ) hemoglobin values were associated with an adverse outcome. The frequencies of perinatal death, low birth weight, and preterm delivery were greater with high than with intermediate hemoglobin. Blankson ML et al ${ }^{9}$ and Rasmussen et $a l^{11}$ observed correlation with high hemoglobin

\section{STUDIES CORRELATING EFFECT OF FIRST} TRIMESTER HEMOGLOBIN PERCENTAGE

The mechanisms that operate by which poor iron status may affect birth weight and preterm births remains poorly understood. A few tested hypotheses are

I. Poor iron status may affect immune function adversely and thus increase the host susceptibility to genital tract infections.

II. Iron deficiency may increase the stress hormones norepinephrine and cortisol.

III. Low hemoglobin concentration may cause chronic hypoxia, which can activate the body's stress response and thus increase circulating levels of corticotrophin releasing hormone, and

IV. Iron deficiency may increase oxidative stress of the placenta.

\begin{tabular}{|c|c|}
\hline Author, Year & Effect of Maternal Anemia on Newborn size and maturity \\
\hline In Present Study & $\begin{array}{l}\text { In anemic mothers low birth weight babies were } 25 \text { out of total } 37 \text { that is } 67.56 \% \text { while in non- } \\
\text { anemic babies mothers low birth weight babies were } 12 \text { of } 37 \text { that is } 32.43 \% \text { statistically signicant } \\
\text { difference noted. }(p<0.001) \text {. }\end{array}$ \\
\hline Muhamad Owais Ahmad et $a /^{13} 2011$ & $\begin{array}{l}\text { The number of low birth weight infants }(64 \%) \text { was statistically very highly significantly more } \\
\qquad(p<0.001) \text { anemic }\end{array}$ \\
\hline
\end{tabular}

\section{OTHER IMPORTANT OBSERVATIONS}

1. Prevalence of anemia in study population.

Prevalence of anemia in our study in urban setting in tertiary care hospital in India, especially in pregnant women is $54 \%$. The FOGSI- WHO25 has estimated that prevalence of anemia in developed and developing countries in pregnant women as $14 \%$ and $51 \%$ respectively. and 65-75 per cent in India. National Nutrition Monitoring Bureau (NNMB) 26 DLHS and ICMR surveys showed that over 70 per cent of pregnant women and adolescent girls in the country were anemic.Various studies conducted by Kalaivani K et al 27 and Patra, Puri and Trivedi et al 17 observed prevalence of anemia as $87 \%$ and $56.9 \%$ respectively.

National programme to give iron supplementation to all pregnant women.

Programme for prevention and management of anemia (NACP) 30India was the first developing country to take up a national programme to prevent anemia among pregnant women and children. The programme envisaged that all pregnant women will be screened for anemia. Non anemic women would get iron $(100 \mathrm{mg}$ ) and folate (500 microgram) and those with anemia should get two tablets daily.

\section{Safe hemoglobin range, where no intervention} is necessary.

We observed better neonatal outcome in the form of weight and anthropometry if maternal preconception hemoglobin is in range of 10 to $13 \mathrm{gm} \%$. After extrapolating neonatal outcome in study group and available data from other studies, we recommend iron prophylaxis in this group and no treatment above this hemoglobin percentage.

\section{U shape correlation between hemoglobin concentration and newborn size-}


In several studies, a U-shaped association was observed between maternal hemoglobin concentrations and birth weight. Abnormally high hemoglobin concentrations usually indicate poor plasma volume expansion, which is also a risk for low birth weight. Lower birth weights in anaemic women have been reported in several studies. ${ }^{7,15,21,31}$ In our study, in first trimester clustering of normal birth weight was observed in hemoglobin $(\mathrm{Hb})$ range of 9.0 to $13.0 \mathrm{gm} \%$ and percentage of LBW was increased as hemoglobin drops below $9.0 \mathrm{gm} \%$ and also when hemoglobin is above $14 \mathrm{gm} \%$. We also observed, high hemoglobin percentage above $14 \mathrm{gm} \%$ was not positively associated with proportionate increase in newborn size as noted with $U$ shape correlation of maternal hemoglobin with newborn size and gestational age. Such correlation was unable to draw because sample number in our study was not sufficient enough to make meaningful conclusions.

\section{CONCLUSION}

Anemia in pregnancy has a recognizable association with fetal outcome. Increased incidence of low birth weight babies is seen if the mother is anemic in her first trimester with significant association when hemoglobin is less than $8 \mathrm{gm} \%$. Increased incidence of preterm deliveries is seen if the mother is anemic in her first trimester. We observed better neonatal outcome in the form of weight and anthropometry if maternal hemoglobin is in range of 10 to $13 \mathrm{gm} \%$. Supplementing iron earlier during antenatal period and maintaining optimal hemoglobin concentration between 10 to $13 \mathrm{gm}$ percent has overall better outcome regarding premature deliveries and low birth weight babies. Regular antenatal care from first trimester has a vital role in assessing and managing maternal anemia timely and it directly affects the perinatal outcome

\section{REFERENCES}

1. Rasmussen KM. Is there a causal relationship between iron deficiency or iron- Deficiency anemia and weight at birth, length of gestation and perinatal mortality? J Nutr 2001; 131: 590S-603S.

2. Alwan NA, Greenwood DC, Simpson NA, McArdle HJ, Godfrey KM, Cade JE. Dietary iron intake during early pregnancy and birth outcomes in a cohort of British women. Hum Reprod. 2011; 26(4):911-919.

3. Muhammad Owais Ahmad, Umay Kalsoom, Ume Sughra, Usman Hadi, Muhammad Imran Effect Of Maternal Anemia On Birth Weight J Ayub Med Coll Abbottabad 2011;23(1)

4. Umber Jalil Bakhtiar, Yasmeen Khan, Razia Nasar Relationship between maternal hemoglobin and Perinatal outcome Rawal Med J 2007;32:102-104).
5. F Nasiri-Amiri, M Hajiahmadi, Z Basirat - Maternal hematocrit status affecting pregnancy outcomeIranian Red Crescent Medical Journal IRCMJ F 2007; 9(2):104- 108

6. Levy A, Fraser D, Katz M, Mazor M, Sheiner E. Maternal anemia during pregnancy is an independent risk factor for low birth weight and preterm delivery. Eur J Obstet Gynec Reprod Biol 2005; 122: 182-6

7. Patra S, Pasrija S, Trivedi S, Puri M. Maternal and perinatal outcome in patients with severe anemia in pregnancy. Int J Gynaecol Obstet 2005; 91: 164-5.

8. Lone, F. W., Qureshi, R. N. and Emanuel, F. (2004), Maternal anemia and its impact on perinatal outcome. Tropical Medicine and International Health, 9: 486-490.

9. Malhotra M, Sharma JB, Batra S, Sharma S, Murthy NS, Arora R. Maternal and perinatal outcome in varying degrees of anemia. Int J Gynaecol Obstet 2002; 79: 93-100.

10. Bondevik GT, Lie RT, Ulstein M, Kvale G. Maternal hematological status and risk of low birth weight and preterm delivery in Nepal. Acta Obstet Gynecol Scand.2001; 80 (5):402-408.

11. Lindsay H Allen; Anemia and Iron Deficiency- Effects on pregnancy outcome; American Journal of Clinical Nutrition, Vol. 71, No. 5, 1280S- 1284 s, May 2000

12. Zhou LM, Yang WW, Hua JZ, Deng CQ, Tao X, Stoltzfus RJ. Relation of hemoglobin measured at different times in pregnancy to preterm birth and low birth weight in Shanghai, China. Am J Epidemiol. 1998; 148(10):998-1006.

13. Scholl TO, Hediger ML, Fischer RL, Shearer JW. Anemia vs iron deficiency: increased risk of preterm delivery in a prospective study. Am J Clin Nutr. 1992; 55(5):985-988.

14. Sloan NL, Jordan E, Winikoff B. Effects of iron supplementation on maternal hematologic status in pregnancy. Am J Public Health 2002; 92: 288-93.

15. Ezzati M, Lopus AD, Dogers A, Vander HS, Murray C. Selected major risk factors and global and regional burden of disease. Lancet 2002; 360: 1347-60.

16. DLHS on RCH. Nutritional status of children and prevalence of anemia among children, adolescent grils and pregnant women 2002-2004.

17. Kalaivani K. Prevalence and consequences of anemia in pregnancy. Indian J Med Res 2009;130:627-33

18. Mohanty C, Prasad R, Srikanth Reddy A, Ghosh JK, Singh TB, Das BK. Maternal anthropometry as predictors of low birth weight. J Trop Pediatr 2006; 52 (1):24-9.

19. Zhang Q, Ananth CV, Li Z, Smulian JC. Maternal anemia and preterm birth: A prospective cohort study. Int J Epidemiol 2009; 38:1380-9.

20. Planning Commission. GOI. Tenth Five-Year Plan 20022007. Sectoral Policies and Programmes. Nutrition. Government of India, New Delhi; 2002

21. Hemminki E, Rimpela U. Iron supplementation, maternal packed cell volume, and fetal growth. Arch Dis Child 1991; $66: 422$.

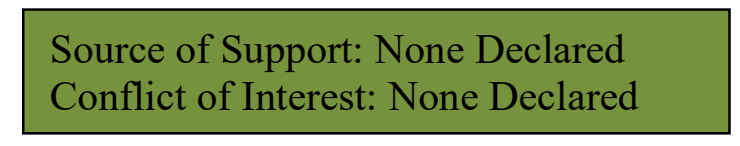

Policy for Articles with Open Access:

Authors who publish with MedPulse International Journal of Gynaecology, (Print ISSN: 2579-0870) (Online ISSN: 2636-4719) agree to the following terms: Authors retain copyright and grant the journal right of first publication with the work simultaneously licensed under a Creative Commons Attribution License that allows others to share the work with an acknowledgement of the work's authorship and initial publication in this journal.

Authors are permitted and encouraged to post links to their work online (e.g., in institutional repositories or on their website) prior to and during the submission process, as it can lead to productive exchanges, as well as earlier and greater citation of published work. 